\section{Raman Characterization of Phenyl-Derivatives: From Primary Amine to Diazonium Salts}

\section{Abstract}

The objective of the present work is to use Raman spectroscopy for characterizing, the fate of phenyl-derivatives, from phenyl-amines to aryl-diazonium derivatives (ADD). Four ADD were investigated: (i) benzene diazoniumtetrafluoroborate (DS), (ii) 4-decyl benzene diazoniumtetrafluoroborate $\left(D S-\mathrm{C}_{10} \mathrm{H}_{21}\right)$, (iii) 4-carboxybenzene diazoniumtetrafluoroborate (DS-COOH) and (iv) 4-(aminoethyl) benzene diazoniumtetrafluoroborate $\left(\mathrm{DS}-\left(\mathrm{CH}_{2}\right)_{2} \mathrm{NH}_{2}\right)$. Raman investigation of the above ADD confirmed the existence of an $\mathrm{N}=\mathrm{N}$ bond stretching in the range of $2285-2305 \mathrm{~cm}^{-1}$. Moreover, the strong band related to $\mathrm{CH}$ in plane-bending and $\mathrm{C}-\mathrm{N}$-stretching modes in the $1073-1080 \mathrm{~cm}^{-1}$ range, is a signature of phenyl derivatives stemming from ADD. Furthermore, we analyzed and discuss the $\mathrm{H}-\mathrm{N}$ (ring) symmetric stretching modes and the ring- $\mathrm{N}$, as well as the benzene-ring vibrational modes, the $\mathrm{C}-\mathrm{H}$ related vibrations and the functions in para-position carried by the aromatic ring. The effect of structural changes, the conformational rearrangements from amines to ADD and the influence of the substituent located in the para-position on Raman modes, were examined as well. Finally, Raman experiments supported by Density Functional Theory (DFT) modeling allowed us to determine the crystalline structure of DS-COOH.

Keywords: Phenyl-amines; Diazonium salts; Synthesis and characterization; Raman; DFT calculations

Abbreviations: ADD: Aryl-diazonium derivatives; DS: Benzenediazoniumtetrafluoroborate; DS-COOH: 4-Carboxybenzene diazoniumtetrafluoroborate; $\mathrm{DS}-\mathrm{C}_{10} \mathrm{H}_{21}$ : 4-decyl benzenediazoniumtetrafluoroborate; DS- $\left(\mathrm{CH}_{2}\right)_{2} \mathrm{NH}_{2}: 4$-(aminoethyl) benzenediazoniumtetrafluoroborate; DFT: Density functional theory; NBO: Natural bond orbital.
Betelu $\mathrm{S}^{1}$, Tijunelyte $\mathrm{I}^{2}$, Boubekeur-Lecaque $\mathrm{L}^{3}$, Ignatiadis I, Schnepf AC ${ }^{1}$, Guenin $E^{2}$, Bouchemal N², Felidj $\mathrm{N}^{3}$, Rinnert $\mathrm{E}^{4}$ and Lamy de la Chapelle $\mathbf{M}^{2}$

1 BRGM, Water Environment and EcoTechnology Division, F-45060 Orléans Cedex 02, France

2 University Paris 13, Sorbonne Paris Cité, CSPBAT laboratory, UMR 7244 CNRS, UFR SMBH, 74, Rue Marcel Cachin, 93017 Bobigny, France

3 University Paris Diderot, Sorbonne Paris Cité, ITODYS, UMR 7086 CNRS, 15 rue J-A de Baîf, 75205 Paris Cedex 13, France

4 IFREMER, Brittany Center,

Measurements, Detection and Sensors Laboratory, CS10070, 29280 Plouzané, France

Corresponding author: Betelu S

s.betelu@brgm.fr

Water Environment and Eco-Technology Division, F-45060 Orléans Cedex 02, France.

Tel: 0033238643268

Fax: 0033238644797

Citation: Betelu S, Tijunelyte I, BoubekeurLecaque L, et al. Raman Characterization of Phenyl-Derivatives: From Primary Amine to Diazonium Salts. J Org Inorg Chem. 2017, 3:1.

\section{Introduction}

Aryl-diazonium derivatives (ADD) are a class of highly useful reaction intermediates, or reagents. Their salts are generally obtained from the diazotization of aromatic amines in the presence of tetrafluoroboric acid, hexafluorophosphate or hexafluoroantimonate [1]. Aryl-diazonium salts are widely used in organic chemistry as reactants for different syntheses. For instance, the process of nitrogen elimination from diazonium cations is a fundamental stage of the Meerwein [2] and Sandmeyer $[3,4]$ reactions. For both of these reactions, improving the yield depends on the application of diazonium salts that effectively lose dinitrogen $\left(\mathrm{N}_{2}\right)$.

The rise in popularity of aryl-diazonium salts has further resulted from their efficiency in surface functionalization, where covalently attached coatings on (semi)-conducting materials bear a wide range of functional groups [5-14]. In addition, the grafting can be accomplished by either chemical (spontaneous grafting), electrochemical, or physical methods [5-12,15]. Surface 
functionalization using diazonium salts has thus become one of the most powerful methods for coatings $[8,13,14]$ through linking (bio)molecules [16,17], polymers [18-20] or nanoparticles [21]. The resulting high-performance materials show improved chemical and physical properties and find widespread application [22].

Whatever the diazonium salt application, identification of the molecular bonds is of great importance for investigating, improving and/or controlling reaction pathways. Raman has been selected as one of the most accurate spectroscopic techniques for determining specific vibrational modes and thus for identifying the molecular bonds and structures.

In this work, four ADD were synthetized and investigated:

- benzene diazoniumtetrafluoroborate (DS),

- 4-carboxybenzene diazoniumtetrafluoroborate (DS- $\mathrm{COOH}$ ),

- 4-decyl benzene diazoniumtetrafluoroborate (DS- $\mathrm{C}_{10} \mathrm{H}_{21}$ ), and

- 4-(aminoethyl) benzene diazoniumtetrafluoroborate (DS$\left.\left(\mathrm{CH}_{2}\right)_{2} \mathrm{NH}_{2}\right)$.

The choice of aryl-diazonium salts was further motivated by the development of robust "long-life" (bio) sensors, as they can be used for surface functionalization in order to provide accurate pre-concentration of (bio) organic compounds for sensitive and reproducible sensing. The physical and chemical properties of the salts related to their interaction ability are summarized hereafter. DS is the simplest salt; it was chosen as a reference and because of the availability of the aromatic cycle for $\pi-\pi$ stacking. DS- $\mathrm{C}_{10} \mathrm{H}_{21}$ has a long non-polar alkyl chain, whose lipophilic and hydrophobic character serves to pre-concentrate non-polar molecules. DS-COOH and DS- $\left(\mathrm{CH}_{2}\right)_{2} \mathrm{NH}_{2}$ can both be used for coupling biomolecules, or for pre-concentrating polar molecules.

We used Raman spectroscopy for characterizing the fate of these four phenyl-derivatives, from phenyl-amine derivatives to ADD. Of particular interest are $\mathrm{N} \equiv \mathrm{N}$ group vibrations, $\mathrm{H}-\mathrm{N}$-(ring) symmetric stretching modes, ring- $\mathrm{N}$ as well as benzene-ring vibrational modes, $\mathrm{C}-\mathrm{H}$ related vibrations, and para functions carried by the aromatic ring, all of which are analyzed and discussed. For some bands, we examined the effect of structural changes as well as of conformational rearrangements, from amine to diazonium salt. The influence of the substituent located in the para position is discussed, especially in terms of the nature and force of the substituent [the mesomeric effect (-M) provided by $\mathrm{COOH}$ as well as the inductive effect (-I) provided by $\mathrm{NH}_{2}$ and $\mathrm{CH}_{3}$ carried by $\mathrm{CH}_{2} \mathrm{CH}_{2} \mathrm{NH}_{2}$ and $\mathrm{C}_{10} \mathrm{H}_{21}$ substituents]. The selection of these four ADD justifies why the mesomeric effect induced by electron-donating groups $(+M)$ has not been investigated in the present work.

In addition, Density Functional Theory (DFT) calculations and Natural Bond Orbital (NBO) charges were performed for DS$\mathrm{COOH}$ in order to conduct the band assignment and to strengthen Raman-spectra interpretation.

\section{Materials and Methods}

\section{Reagents}

The reagents used were sodium nitrite $\left(\mathrm{NaNO}_{2}\right)$, tetrafluoroboric acid $\left(\mathrm{HBF}_{4}\right)$, diethyl ether (>98\%, ACS reagent), aniline, 4-docylaniline, 4-aminobenzoic acid, 4-(2-aminoethyl)-aniline, purchased from Sigma Aldrich Chimie S.a.r.I (St. Quentin Fallavier, 38297 France).

\section{Synthesis and purification of diazonium salts}

Diazonium salts were obtained by oxidation of the corresponding aryl-amine at $0^{\circ} \mathrm{C}$ and using sodium nitrite [7]. For the four different diazonium salts, $4 \mathrm{mmol}$ of the corresponding amine were mixed with $2 \mathrm{~mL}$ of tetrafluoroboric acid dissolved in $7 \mathrm{~mL}$ of milli-Q water. The mixtures were then cooled in ice for $15 \mathrm{~min}$ ( 1 hour for that containing 4-docyl-aniline). Afterwards, a solution of $300 \mathrm{mg}$ ( $600 \mathrm{mg}$ for the mixture containing 4-docyl-aniline) of sodium nitrite dissolved in less than $1 \mathrm{~mL}$ of milli-Q water was added drop-by-drop. During the reaction the temperature was maintained at $0^{\circ} \mathrm{C}$. After two hours of reaction ( 96 hours for the mixture containing 4-docyl-aniline), the mixture was filtered through $0.2 \mu \mathrm{m}$ cellulose ester filters (Whatman, France) and thoroughly washed with cold diethyl ether.

Diazonium salt purification consisted in dissolving the crude solid in a small amount of deionized water, followed by recrystallization in diethyl ether. The recrystallization procedure lasted for 48 hours at $6^{\circ} \mathrm{C}$. Recrystallized diazonium salts were then filtered ( $0.2 \mu \mathrm{m}$ of cellulose ester filters, Whatman, France), dried and stored at $-20^{\circ} \mathrm{C}$.

\section{Raman measurements}

Raman measurements were recorded on pure chemicals (as powder unless otherwise stated) with a Labram HR800 Raman microspectrometer (HORIBA Jobin Yvon SAS, 59650 Villeneuve d'Ascq, France). For both amines and diazonium salts, a robust laser diode at $691 \mathrm{~nm}$ (Ondax) that is suitable for many Raman applications [23] was used to avoid molecular resonance. For diazonium salts and the 4-aminobenzoic acid, the scattered light was collected by a $100 x$ objective with a numerical aperture (N.A.) of 0.9. For liquid compounds (aniline, 4-(2-aminoethyl) aniline and 4-decylaniline), a water immersion objective (100x, N.A.=1.0) was used. Spectral resolution was less than $2 \mathrm{~cm}^{-1}$ and spectral calibration was performed daily via a silicon sample. All presented spectra were baseline corrected and normalized using the spectrometer software (LabSpec, HORIBA Jobin Yvon). Each spectrum was normalized to its maximum intensity. For calculations, spectra were normalized regarding the $\mathrm{C}=\mathrm{C}$ stretching mode [24] observed between 1570 and $1611 \mathrm{~cm}^{-1}$.

\section{Nuclear Magnetic Resonance (NMR) measurements}

Synthesized diazonium salts and their primary amines were also characterized by NMR measurements. Spectra were recorded using a Bruker Avance III $400 \mathrm{MHz}$ instrument (Bruker UK Ltd, Coventry CV4 9GH, United Kingdom). The procedure, NMR 
spectra and ${ }^{1} \mathrm{H}$ chemical shifts are presented in the Supporting Information. The structure of the salts as well as the indexation of protons is presented in Scheme 1. RMN spectra of both amines and diazonium salts are presented on Figure S1 in Supporting Information.

\section{Computational details}

All calculations were carried out using the Gaussian 09 suite of programs [25] using the B3LYP exchange and correlation functional $[26,27]$ along with the $6-311++G(d, p)$ basis set for all atoms. The structures were optimized without symmetry constraint (see Supporting Information). The vibrational wavenumbers and normal modes were calculated within their harmonic approximation. A scaling factor of 0.976 was chosen on the basis of previously published work [28].

\section{Results and Discussion}

Figures 1-4 compare Raman spectra obtained for A) primary amines and B) corresponding synthesized diazonium salts.

The wavenumbers of important peaks are reported in Table 1 and their assignments were provided from the literature $[24,29,30]$ The spectrum obtained for aniline is in a good agreement with the one provided by Badawi [24]; most of their band assignments

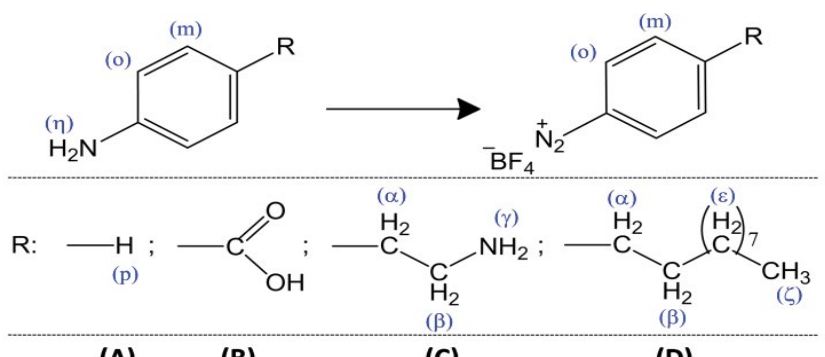

(A) (B)

(C)

(D)

Scheme 1 Structures of amine and diazonium salt with the indexation of protons.

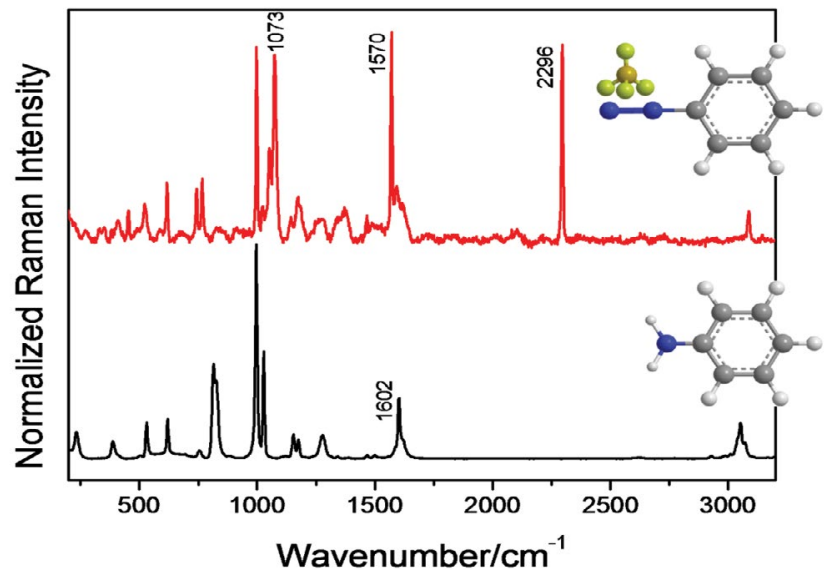

Figure 1 Raman spectra of aniline (black spectrum) and the corresponding diazonium salt benzene diazonium tetra fluoroborate, DS (red spectrum). Each spectrum was normalized to its maximum intensity.

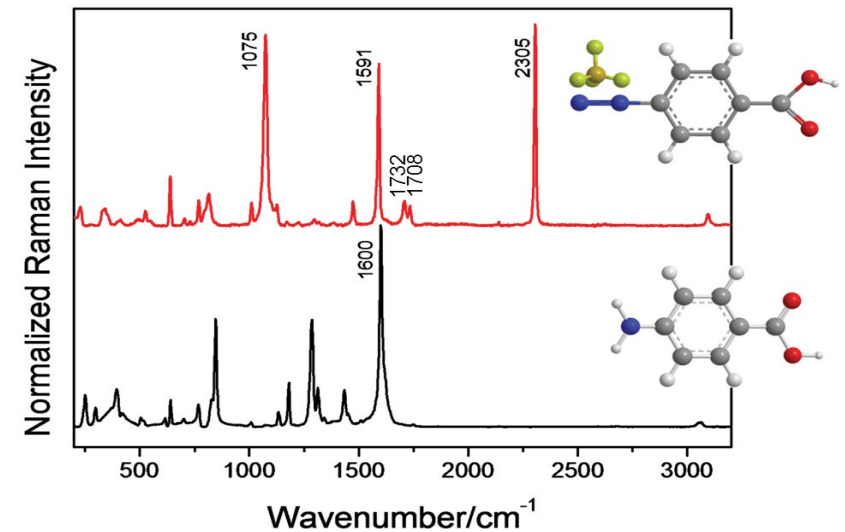

Figure 2 Raman spectra of 4-aminobenzoic acid (black spectrum) and the corresponding diazonium salt 4-carboxy benzene diazonium tetra fluoroborate, DS- $\mathrm{COOH}$ (red spectrum). Each spectrum was normalized to its maximum intensity.

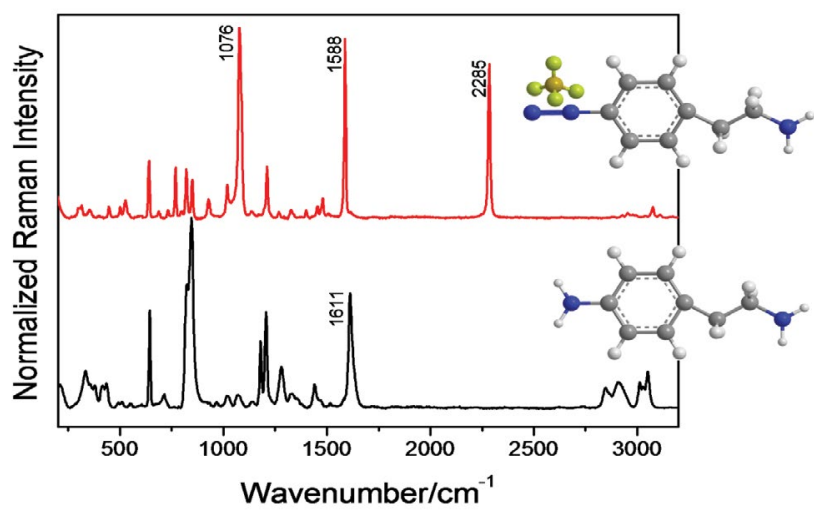

Figure 3 Raman spectra of 4-(2-aminoethyl) aniline (black spectrum) and the corresponding diazonium salt DS- $\left(\mathrm{CH}_{2}\right)_{2} \mathrm{NH}_{2}$ (red spectrum). Each spectrum was normalized to its maximum intensity.

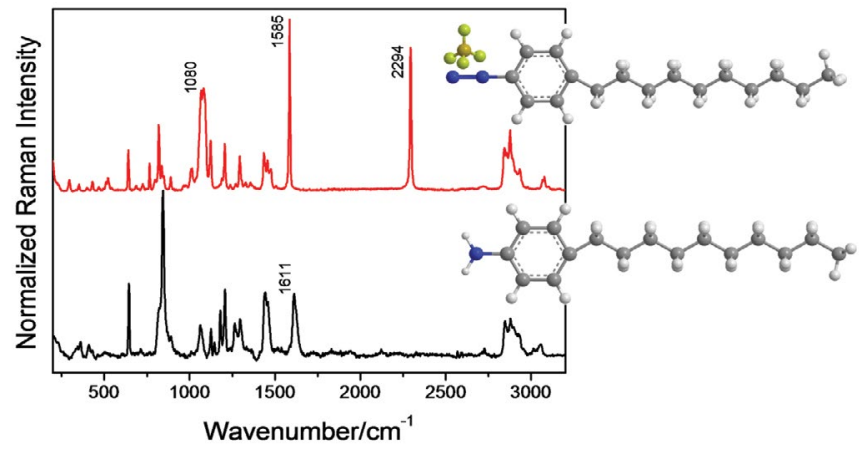

Figure 4 Raman spectra of 4-decylaniline (black spectrum) and the corresponding diazonium salt 4-decyl benzene diazonium tetra fluoroborate, $\mathrm{DS}-\mathrm{C}_{10} \mathrm{H}_{21}$ (red spectrum). Each spectrum was normalized to its maximum intensity.

were used as reference for this work.

In addition, interactions can occur between two salts in a crystalline state, especially for DS- $\mathrm{COOH}$ because carboxyphenyl- 
Table 1 Universal band assignments for Raman spectra obtained experimentally for primary amines and for the corresponding diazonium salts.

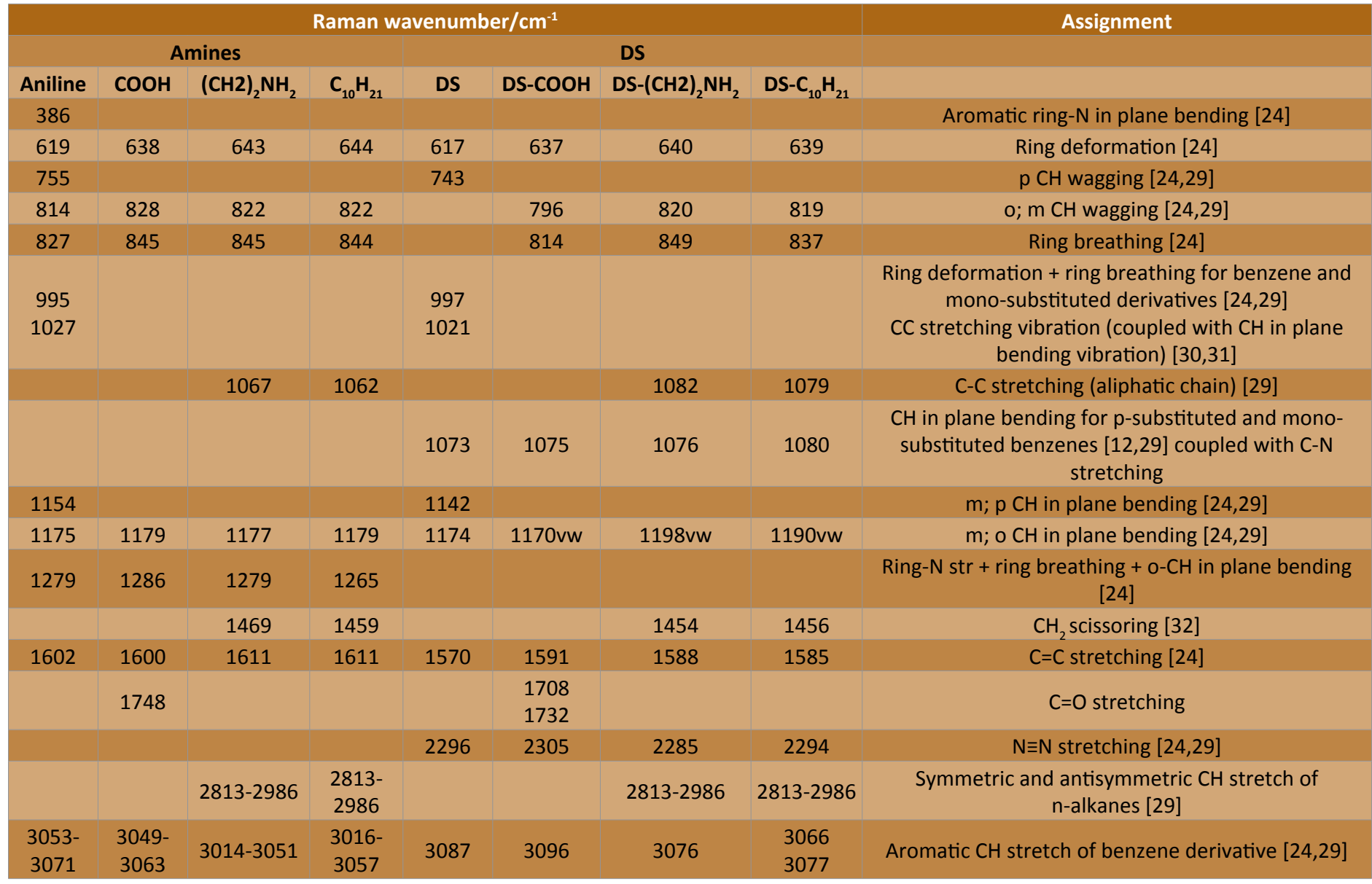

derivatives are both $\mathrm{H}$-bonding donor and acceptor. Thus, they preferentially self-organize as dimers in the crystalline state [33-35]. To investigate the dimer formation and obtain a clear assignment of the DS-COOH Raman bands, DFT calculations and Natural Bond Orbital (NBO) charges were carried out, examining two models. The first one considered monomer units (named $\mathrm{CBN}_{2}$ ) whereas the second one considered DS-COOH dimers (named $\mathrm{CBN}_{2}$ dimer). Figure $\mathbf{5 A}$ shows a comparison between the Raman spectrum for DS-COOH and the calculated vibrational features of the monomer $\left(\mathrm{CBN}_{2}\right)$ and the dimeric arrangement via $\mathrm{H}$-bonds $\left(\mathrm{CBN}_{2}\right.$ dimer). The Raman band assignments of important peaks are shown on Table 2. The crystalline state of DS- $\mathrm{COOH}$ regarding the $\mathrm{CBN}_{2}$ and $\mathrm{CBN}_{2}$ dimer models is discussed over the presentation of the different investigated modes of phenyl-derivatives.

\section{$\mathrm{N} \equiv \mathrm{N}$ group vibrations}

The particularity of diazonium salts is their $\mathrm{N}_{2}{ }^{+}$function obtained by oxidation of the corresponding amine. The strong peaks observed at 2296, 2305, 2285 and $2294 \mathrm{~cm}^{-1}$ for DS, DS-COOH, DS- $\left(\mathrm{CH}_{2}\right)_{2} \mathrm{NH}_{2}$ and DS- $\mathrm{C}_{10} \mathrm{H}_{21}$, respectively, (Figures 1-4; Table 1) on the salt spectra compared to aniline ones, are due to the $\mathrm{N} \equiv \mathrm{N}$ bond $[12,29]$. Compared to the experimental data acquired for each compound, the DFT calculations on DS- $\mathrm{COOH}$ revealed strong similarities in this spectral range (Figure 5, Table 2). The calculated position for the $\mathrm{N} \equiv \mathrm{N}$ stretching mode was found at $2293 \mathrm{~cm}^{-1}$ for $\mathrm{CBN}_{2}$ and at $2304 \mathrm{~cm}^{-1}$ for $\mathrm{CBN}_{2}$ dimer. The similarity between the latter theoretical position and the experimental

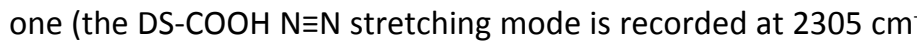
$\left.{ }^{1}\right)$ strengthens the fact that the best model for reproducing the vibrational features of the normal Raman spectra is a dimeric arrangement of the diazonium cation via $\mathrm{H}$-bonds.

According to the literature $[29,36]$, the position of the $N \equiv N$ vibration mode depends upon the nature of the ring substituent located in the para-position of a diazonium salt. Our results show that substituents have a rather low effect on the $\mathrm{N} \equiv \mathrm{N}$ fragment following the observed wavenumber shifts (Table 1; Figure S2 in Supporting Information). For DS- $\mathrm{COOH}$, however, the $\mathrm{COOH}$ electron-withdrawing tendency was confirmed by calculation of the $\mathrm{C}_{\mathrm{N} \equiv \mathrm{N}} \mathrm{NBO}$ charges. Indeed, the $\mathrm{C}_{\mathrm{N} \equiv \mathrm{N}(\mathrm{DS}-\mathrm{COOH})} \mathrm{NBO}$ charge is equal to 0.012 compared to the $C_{N=N(D S)} N B O$ charge that is 0.003 . As a result, a shift of $+9 \mathrm{~cm}^{-1}$ of the $\mathrm{N} \equiv \mathrm{N}$ vibration mode was found for DS-COOH relative to DS. The electron-withdrawing groups (i.e., $\mathrm{COOH}$ ) induce an increase of the contribution of a structure like $\square-\mathrm{N}^{+} \equiv \mathrm{N}$ and $+\square=\mathrm{N}^{+}=\mathrm{N}^{-}$and hence induce a shift of the $\mathrm{N} \equiv \mathrm{N}$ stretching vibration to higher wavenumbers $[29,36]$. This agrees with the $\mathrm{N} \equiv \mathrm{N}$ bond-length decrease [36] and is also consistent with the polarizability increase of the $\mathrm{N} \equiv \mathrm{N}$ bond. Experimental data show in fact that the relative intensity of the $\mathrm{N} \equiv \mathrm{N}$ bond is increased by $23 \%$ for DS- $\mathrm{COOH}$ compared with that obtained for DS, DS- $\mathrm{C}_{10} \mathrm{H}_{21}$ and DS- $\mathrm{CH}_{2} \mathrm{CH}_{2} \mathrm{NH}_{2}$ (Figure S2 and Table S1 in Supporting Information) 


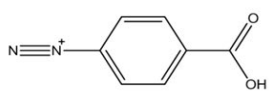

$\mathrm{CBN}_{2}$

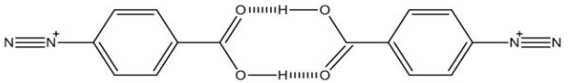

$\mathrm{CBN}_{2}$ dimer

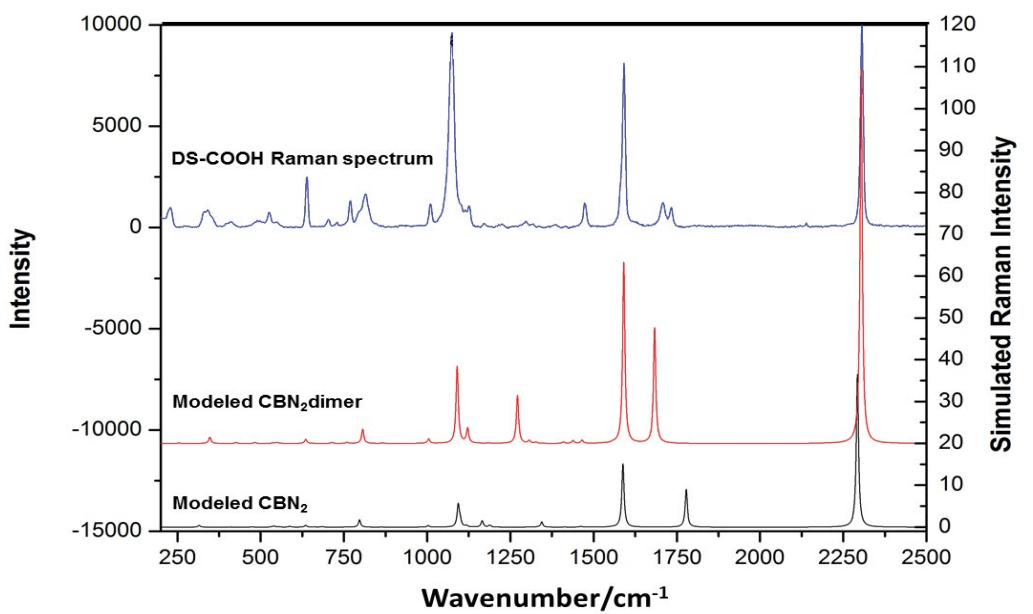

Figure 5 Comparison of the experimental Raman spectrum recorded for DS- $\mathrm{COOH}$ and the calculated vibrational features of the salt, by considering monomer $\left(\mathrm{CBN}_{2}\right)$ and dimeric arrangements via $\mathrm{H}$-bonds $\left(\mathrm{CBN}_{2}\right.$ dimer).

Table 2 Comparison of experimental and calculated wavenumbers considering $\mathrm{CBN}_{2}$ and $\mathrm{CBN}_{2}$ dimer for modeling. Assignments of the main peaks. $\times$ Calculated $\mathrm{CBN}_{2}$ dimer features a center of symmetry imposing the mutual exclusion rule for vibrational modes. In this framework, the $v_{\text {sym }}(\mathrm{C}=\mathrm{O})$ is Raman active while $v_{\text {asym }}(\mathrm{C}=0)$ is Raman inactive.

\begin{tabular}{|c|c|c|c|c|}
\hline DS-COOH & \multicolumn{2}{|c|}{$\mathrm{CBN}_{2}$} & \multicolumn{2}{|c|}{$\mathrm{CBN}_{2}$ dimer } \\
\hline Experimental $/ \mathrm{cm}^{-1}$ & Calculated $/ \mathrm{cm}^{-1}$ & Assignment & Calculated $/ \mathrm{cm}^{-1}$ & Assignment \\
\hline \multirow[t]{2}{*}{2305} & 2293 & $v(\mathrm{~N} \equiv \mathrm{N})$ & 2304 & $v(\mathrm{~N} \equiv \mathrm{N})$ \\
\hline & 1778 & $v(\mathrm{C}=\mathrm{O})$ & & \\
\hline 1708 & & & 1684 & $v_{\text {sym }}(\mathrm{C}=\mathrm{O})$ \\
\hline 1732 & & & $x$ & $v_{\text {asym }}(\mathrm{C}=\mathrm{O})$ \\
\hline 1591 & 1588 & $v(\mathrm{C}=\mathrm{C})$ & 1590 & $v(\mathrm{C}=\mathrm{C})$ \\
\hline \multirow[t]{2}{*}{1293 wwV } & 1344 & $v(\mathrm{CO}-\mathrm{H})$ & 1271 & $v_{\text {sym }}(\mathrm{CO}-\mathrm{H})$ \\
\hline & 1165 & $v(\mathrm{C}-\mathrm{H})$ in plane and $v(\mathrm{CO}-\mathrm{H})$ & & \\
\hline 1127 ww & & & 1122 & $v(\mathrm{C}-\mathrm{H})$ in plane \\
\hline 1075 & 1093 & $\begin{array}{c}v(\mathrm{C}-\mathrm{H}) \text { in plane, } v(\mathrm{C}-\mathrm{N}) \text { and } \\
v(\mathrm{C}-\mathrm{O})\end{array}$ & 1090 & $v(\mathrm{C}-\mathrm{H})$ in plane, $v_{\text {sym }}(\mathrm{C}-\mathrm{N})$ \\
\hline 814 & 797 & Ring breathing & 807 & Ring breathing \\
\hline
\end{tabular}

On the contrary, electron-donating groups located in parapositions induce an increase in the contribution of a structure like 《 $-\mathrm{N}^{+} \equiv \mathrm{N}$ and $+\Longrightarrow=\mathrm{N}^{+}=\mathrm{N}^{-}$and, hence, a decrease of the $\mathrm{N} \equiv \mathrm{N}$ stretching vibration wavenumber. Such shifts are effectively observed in our experimental results since shifts of $-11 \mathrm{~cm}^{-1}$ and $-2 \mathrm{~cm}^{-1}$ of the $\mathrm{N} \equiv \mathrm{N}$ vibration mode were evaluated for $\mathrm{DS}-\left(\mathrm{CH}_{2}\right)_{2} \mathrm{NH}_{2}$ and DS- $\mathrm{C}_{10} \mathrm{H}_{21}$, respectively, compared to that observed for DS. Of the two electron-donating groups $\mathrm{CH}_{3}$ and $\mathrm{NH}_{2}, \mathrm{NH}_{2}$ has the higher inductive effect $\left[\mathrm{NH}_{2}\right.$ substituent constants $\left(\sigma_{\mathrm{p}}\right)=-0.66$; $\mathrm{CH}_{3}$ substituent constants $\left.\left(\sigma_{\mathrm{p}}\right)=-0.17\right][37,38]$. Moreover, the inductive effect drops off rapidly with the number of $\sigma$ bonds. This is why:

(i) The negative shift in wavenumber observed for $\mathrm{N} \equiv \mathrm{N}$ vibration for DS- $\mathrm{C}_{10} \mathrm{H}_{21}$ is not significantly different from the one observed for DS, and why (ii) The negative shift in wavenumber observed for $\mathrm{N} \equiv \mathrm{N}$ vibration of DS- $\left(\mathrm{CH}_{2}\right)_{2} \mathrm{NH}_{2}$ is higher than that observed for DS- $\mathrm{C}_{10} \mathrm{H}_{21}$.

\section{$\mathrm{H}-\mathrm{N}$-(ring) symmetric stretching mode}

In addition to the occurrence of an $\mathrm{N} \equiv \mathrm{N}$ stretching vibration, the $\mathrm{N}-\mathrm{H}$ symmetric stretching disappears in the high wavenumber range $3250-3400 \mathrm{~cm}^{-1}$ for primary amines (Figure 6). This indicates the successful synthesis of diazonium salts with a high production rate, which was confirmed by NMR study with the disappearance of the $\eta$ band on the NMR spectra (Supporting Information). Each spectrum was normalized to its maximum intensity.

\section{Ring-N vibrational modes}

According to Badawi [24] and Wojciechowski [30], the peak at $386 \mathrm{~cm}^{-1}$ for the aniline molecule (Figure 1), corresponds to planar 


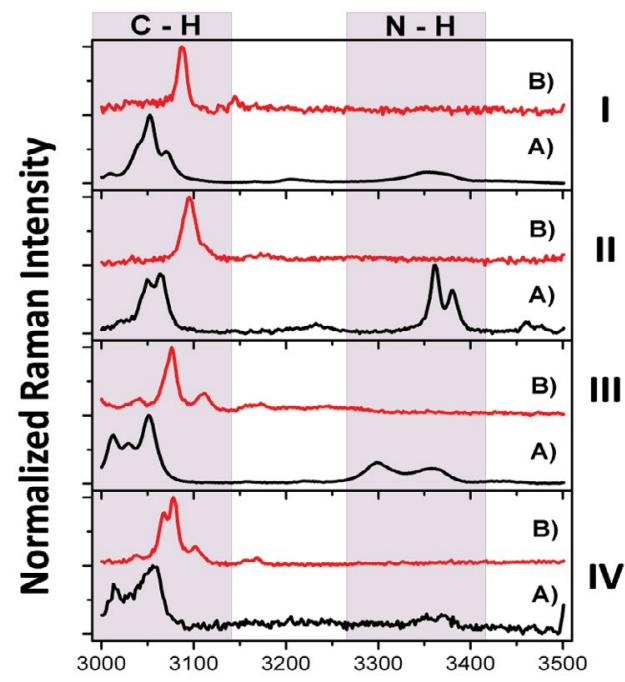

Wavenumber $/ \mathrm{cm}^{-1}$

Figure 6 Comparison of aromatic $\mathrm{C}-\mathrm{H}$ stretching and $\mathrm{N}-\mathrm{H}$ stretching modes between the four synthesized diazonium salts ( $B$ red lines) and the corresponding primary amines (A black lines). Roman numbers I to IV correspond to DS, DS-COOH, DS- $\left(\mathrm{CH}_{2}\right)_{2} \mathrm{NH}_{2}$ and DS$\mathrm{C}_{10} \mathrm{H}_{21}$, respectively.

bending of an aromatic ring-N. However, this vibrational mode is less obvious for para-substituted amines. A possible explanation is that aromatic-ring-vibration modes depend on the mass of the substituent [29]. Thus, in the range of $200-580 \mathrm{~cm}^{-1}$, many vibrational modes can be observed depending on the nature of the para-substituted group (Figures 2-4). The same conclusion is valid for the range of $1250-1290 \mathrm{~cm}^{-1}$, another range where a band corresponding to $\mathrm{C}-\mathrm{N}$ vibration can be located. Raman bands for the amines observed between 1265 and $1279 \mathrm{~cm}^{-1}$ (Table 1) and assigned to ring- $\mathrm{N}$ stretching coupled to ring breathing and to ortho- $\mathrm{CH}$ in plane bending [24], is no longer seen in the diazonium salt spectra.

This effect may be due to significant structural changes and conformational rearrangements, as the theoretical and experimental data provided by literature indicate that the neutral aniline in its ground electronic state $\left({ }^{1} A 1\right)$ is non-planar. The dihedral angle between the $\mathrm{NH}_{2}$ plane and the $\mathrm{C}_{6} \mathrm{H}_{5} \mathrm{~N}$ plane was determined to be $37 \pm 2^{\circ}$, assuming that the $\mathrm{C}-\mathrm{N}$ bond makes an angle of $1.5-2.3^{\circ}$ [30]. In comparison, the corresponding diazonium salt (aryl-diazonium) is a quasi-planar molecule [39], assuming that the $\mathrm{C}-\mathrm{N}$ bond makes an angle of $0.5^{\circ}$ [40]. The main factor causing this quasi-planarity is undoubtedly the strong through-bond interaction between the ring, which is known to be a strong electron donor, and the $\mathrm{N}_{2}$ group, which is the strongest known electron acceptor [39]. In agreement with the literature $[30,39,41]$, this bond lengthens so that co-planarity is maintained. An additional explanation could be related to the electron-charge density redistribution in the $\mathrm{C}-\mathrm{N}$ bond. This is consistent with the observation that the diazonium group is one of the most powerful $\sigma$-electron and $\pi$-electron acceptors [41].

\section{Benzene-ring and $\mathrm{C}-\mathrm{H}$ related vibrations}

By comparing Raman spectra from amines and diazonium salts, several common bands related to benzene-ring vibrations can be observed. First of all, a strong band related to the benzenering stretching mode (Table 1) occurs on all Raman spectra in the range of $1585-1611 \mathrm{~cm}^{-1}$. According to Wojciechowski [30], this band is essentially related to ortho-meta C-C stretching modes. From phenyl-amine derivatives to diazonium salts, this band is the most significant signature of the benzene ring. Compared to the primary amines, this band is shifted to a lower wavenumber for all salts. These shifts are close to $25 \mathrm{~cm}^{-1}$ for salts except DS$\mathrm{COOH}$, maybe due to the higher weight of the $\mathrm{N}_{2}$ group compared to $\mathrm{NH}_{2}$ that induces a decrease of the vibration frequency. In the case of DS- $\mathrm{COOH}$, the shift of less than $10 \mathrm{~cm}^{-1}$ may be due to the dimeric form of the salt that reduces the weight effect of the $\mathrm{N}_{2}$.

Two strong and distinct peaks again assigned to the ringdeformation and ring-breathing modes-coupled with $\mathrm{CH}$ in plane-bending vibration of benzene and of mono-substituted derivatives, are found in the Raman spectrum of aniline around $1000 \mathrm{~cm}^{-1}$ (Figure 1; Table 1, trigonal ring breathing vibration) and $1027 \mathrm{~cm}^{-1}$ (Figure 1; Table 1) [30,31]. For DS, these bands are slightly shifted to 997 and $1021 \mathrm{~cm}^{-1}$. In case of para-substituted amines and diazonium salts (di-substituted benzene derivatives) these vibrational modes are not allowed [29].

Bands assigned to ring deformation ( $\mathrm{C}=\mathrm{C}-\mathrm{C}$ in plane deformation) in the region of 617-644 $\mathrm{cm}^{-1}$ (Table 1) are present for both amines and diazonium salts. In agreement with Socrates [29], the bands shift to a higher wavenumber for para-substituted aromatic compounds compared to mono-substituted compounds.

According to Badawi [24], the vibrational mode at $827 \mathrm{~cm}^{-1}$ (Table 1) for aniline can be assigned to a ring-breathing mode, coupled with ring- $\mathrm{N}$ stretching and ring deformation. This band is shifted to higher wavenumbers $\left(844-845 \mathrm{~cm}^{-1}\right)$ for parasubstituted amines. However, shifts of $-31 \mathrm{~cm}^{-1}$ and $-7 \mathrm{~cm}^{-1}$ toward lower wavenumbers are observed for DS-COOH and DS- $\mathrm{C}_{10} \mathrm{H}_{21}$ respectively, compared to their primary amines, whereas in the Raman spectrum of DS- $(\mathrm{CH})_{2} \mathrm{NH}_{2}$ a shift of $+4 \mathrm{~cm}^{-1}$ was found. In common for all substituted diazonium salts, the intensity of this vibrational mode strongly decreases and is no longer observed in the Raman spectrum of DS. Another vibrational mode at $814 \mathrm{~cm}^{-1}$ assigned o,m-CH wagging (Table 1 and Figures 2-4) was found to behave in similar manner as described above for the ring-breathing mode. The shift of these bands may be due to structural changes and conformational rearrangements caused by the presence of the $\mathrm{N}_{2}{ }^{+}[39,41]$.

Concerning the $\mathrm{C}-\mathrm{H}$ ring related vibrations, bands assigned to $\mathrm{p}-\mathrm{CH}$ wagging-coupled with ring- $\mathrm{N}$ wagging and o- $\mathrm{CH}$ wagging at 755 and $743 \mathrm{~cm}^{-1}$ (Table 1) as well as $\mathrm{m}, \mathrm{p}-\mathrm{CH}$ bending-coupled with ring deformation at 1154 and $1142 \mathrm{~cm}^{-1}$ (Table 1) are only observed for aniline and DS, due to mono-substitution.

The very strong band observed around $1075 \mathrm{~cm}^{-1}$ and assigned to $\mathrm{CH}$ in plane bending-coupled with ring- $\mathrm{N}$ stretching mode for mono- and para-substituted benzenes in diazonium-salt spectra, 
is of particular interest (red spectra on Figures 1-4; Table 1). The appearance of this band is an astonishing phenomenon, explained by electron-charge density redistribution within the structures caused by the presence of $\mathrm{N}_{2}{ }^{+}$. It is also the indisputable signature of phenyl-derivatives stemming from diazonium salts.

According to the literature, aromatic $\mathrm{C}-\mathrm{H}$ symmetric and antisymmetric stretching modes occur above $3000 \mathrm{~cm}^{-1}$ and show a multiplicity of weak to moderate bands [42]. In comparison with amines, $\mathrm{CH}$ stretching (Table 1 ) shifts toward the higher wavenumber for diazonium salts (Figure 6). This shift indicates a strengthening of the $\mathrm{C}-\mathrm{H}$ bond, possibly due to a new charge distribution on the ring after the substitution of $\mathrm{NH}_{2}$ by $\mathrm{N}_{2}^{+}$[30]. This result is in good agreement with the ones in the literature for aniline and its corresponding diazonium salt $[30,39,41]$.

\section{Functions in para- position carried by the aromatic ring}

Concerning the different functions in para-position carried by the aromatic ring $\left(\mathrm{COOH},\left(\mathrm{CH}_{2}\right)_{2} \mathrm{NH}_{2}\right.$ and $\left.\mathrm{C}_{10} \mathrm{H}_{21}\right)$, some characteristic bands have been identified. For $\left(\mathrm{CH}_{2}\right)_{2} \mathrm{NH}_{2}, \mathrm{C}_{10} \mathrm{H}_{21}$ and their corresponding diazonium salts, symmetric and antisymmetric $\mathrm{CH}_{3}$ stretches of $n$-alkanes as well as symmetric $\mathrm{CH}_{2}$ stretches of $\mathrm{n}$-alkanes are clearly identified in the range of $2813-2986 \mathrm{~cm}^{-1}$ (Figures 3 and 4; Table 1). In addition, $\mathrm{C}-\mathrm{C}$ stretching mode occurs in the range of $1062-1082 \mathrm{~cm}^{-1}$ (Table 1 ) and $\mathrm{CH}_{2}$ scissoring in the range of $1454-1469 \mathrm{~cm}^{-1}$ (Table 1). Some significant changes in peak position or intensity occur, meaning that the simple modification of the molecule from aniline form to diazonium salt could have a strong influence on the vibrational modes of the alkyl chain in para-position.

Concerning aminobenzoic acid derivatives (Figure 2; Table 1), the weak bands in the $1700-1750 \mathrm{~cm}^{-1}$ region are characteristic features of the carboxylic group due to $\mathrm{C}=\mathrm{O}$ stretching vibration. They were respectively assigned to symmetric and antisymmetric stretching vibrations at 1708 and $1732 \mathrm{~cm}^{-1}$. The antisymmetric stretch is usually seen at a higher wavenumber than the symmetric one [43]. With regards to DFT calculations (Figure 5; Table 2), the $\mathrm{CBN}_{2}$-model simulated spectrum predicts a single $\mathrm{C}=\mathrm{O}$ stretching mode, $v(\mathrm{C}=\mathrm{O})_{\mathrm{CBN2}}$, at $1778 \mathrm{~cm}^{-1}$. This DFT numerical modeling is in good agreement with the literature [29]: when carbonyl does not interact with a hydrogen bond (the monomer case), the stretching bands appear in the range $1760-1735 \mathrm{~cm}^{-1}$. However, the dimer should be characterized by two $\mathrm{C}=\mathrm{O}$ stretching modes, the symmetric $\mathrm{C}=\mathrm{O}$ one $\left(v_{\text {sym }}(\mathrm{C}=\mathrm{O})_{\mathrm{CBN2} \text { dimer }}\right)$ at $1683 \mathrm{~cm}^{-1}$ and the antisymmetric $\mathrm{C}=\mathrm{O}$ one $\left(v_{\text {asym }}(\mathrm{C}=\mathrm{O})_{\mathrm{CBN} 2 \text { dimer }}\right)$ at $1729 \mathrm{~cm}^{-1}$. With regard to Raman calculations of the $\mathrm{C}=\mathrm{O}$ stretching mode in the $\mathrm{CBN}_{2}$ model $\left(v_{\text {sym }}(\mathrm{C}=\mathrm{O})_{\mathrm{CBN2}}\right.$ at $\left.1778 \mathrm{~cm}^{-1}\right)$, the theoretical shift toward the lower wavelength of the symmetric $\mathrm{C}=\mathrm{O}$ stretching mode in the dimer $\left[v_{\text {sym }}(C=O)_{C B N 2 \text { dimer }}\right.$ at $\left.1683 \mathrm{~cm}^{-1}\right]$ is due to a change in polarizability of the $\mathrm{CO}$ group induced by hydrogen bonding. The simulated Raman spectrum for $\mathrm{CBN}_{2}$ dimer only shows this latter symmetric mode $\left[v_{\text {sym }}(C=O)_{C B N 2 \text { dimer }}\right]$ at $1683 \mathrm{~cm}$ 1. This concurs with the fact that the $\mathrm{CBN}_{2}$ dimer features a center of symmetry imposing a mutual exclusion rule for vibrational modes. In this framework, the $v_{\text {sym }}(\mathrm{C}=\mathrm{O})_{\mathrm{CBN2} \text { dimer }}$ is Raman active, while $v_{\text {asym }}(\mathrm{C}=\mathrm{O})_{\mathrm{CBN2} \text { dimer }}$ is Raman inactive. This mutual exclusion rule explains why the simulated Raman spectrum for an isolated $\mathrm{CBN}_{2}$ dimer only shows symmetric $\mathrm{C}=\mathrm{O}$ stretching.

However, the same dimer considered in the crystal packing has a lower symmetry that suspends the mutual exclusion rule, both $v_{\text {sym }}(\mathrm{C}=\mathrm{O})_{\mathrm{CBN} 2 \text { dimer }}$ and $v_{\text {asym }}(\mathrm{C}=\mathrm{O})_{\mathrm{CBN} 2 \text { dimer }}$ becoming Raman active. This is consistent with the two peaks on the experimental Raman spectrum of DS-COOH for both the symmetric and antisymmetric $\mathrm{C}=\mathrm{O}$ stretching modes. The shift toward a higher wavenumber observed experimentally for symmetric $\mathrm{C}=\mathrm{O}$ stretching from the theoretical $v_{\text {sym }}(C=O)_{\text {CBN2 dimer }}$ value calculated at $1683 \mathrm{~cm}^{-1}$ to the experimentally measured $v_{\text {sym }}(\mathrm{C}=\mathrm{O})_{\mathrm{DS}-\mathrm{COOH}}$ value at 1708 $\mathrm{cm}-1$ is probably caused by the presence of $\mathrm{BF}_{4}-$ in the crystalline structure of $\mathrm{DS}-\mathrm{COOH}$. This agrees with the effect provided by electronegative atoms, which increase the $\mathrm{C}=\mathrm{O}$ stretching vibration wavenumber $[44,45]$. In addition to and in agreement with the results shown on Table $\mathbf{2}$, the similarities between the experimental and the theoretical position of $\mathrm{v}(\mathrm{N} \equiv \mathrm{N}), \mathrm{v}(\mathrm{C}=\mathrm{C})$, ring breathing and $\mathrm{v}(\mathrm{C}-\mathrm{H})$ in plane, $v_{\text {sym }}(\mathrm{C}-\mathrm{N}), v_{\text {sym }}(\mathrm{CO}-\mathrm{H})$ as well as $\mathrm{v}(\mathrm{C}-\mathrm{H})$ in plane confirm the fact that the best model for reproducing the vibrational features of the normal Raman spectra is a dimeric arrangement of DS- $\mathrm{COOH}$ via $\mathrm{H}$-bonds.

\section{Conclusions}

The work consisted in a Raman characterization of synthesized diazonium salts, comparing them with Raman spectra provided for amines. Raman investigation of synthesized diazonium salts confirmed the stretching of the $\mathrm{N} \equiv \mathrm{N}$ bond in the expected spectral range of 2285-2305 $\mathrm{cm}^{-1}\left(2296,2285,2305\right.$, and $2294 \mathrm{~cm}^{-1}$ for DS, DS-COOH, DS- $\left(\mathrm{CH}_{2}\right)_{2} \mathrm{NH}_{2}$ and $D S-\mathrm{C}_{10} \mathrm{H}_{21}$, respectively). The disappearance of the $\mathrm{H}-\mathrm{N}$-(ring) symmetric stretching observed in the range $3299-3361 \mathrm{~cm}^{-1}$ for the primary amines, is another evidence of the effectiveness of salt synthesis. Moreover, our results indicate that the very strong band related to the combination of both $\mathrm{CH}$ in-plane bending for mono- and parasubstituted benzenes as well as $\mathrm{C}-\mathrm{N}$ stretching in the range 1073$1080 \mathrm{~cm}^{-1}$, constitutes an actual spectral signature of the phenylderivatives stemming from diazonium salts.

Furthermore, the fate of phenyl-derivatives has also been examined by using Raman spectroscopy; this covered $\mathrm{N} \equiv \mathrm{N}$ group vibrations, $\mathrm{H}-\mathrm{N}$-(ring) symmetric stretching modes, ring- $\mathrm{N}$ as well as benzene-ring vibrational modes, $\mathrm{C}-\mathrm{H}$-related vibrations and para functions carried by the aromatic ring. We especially considered both

1) The effect of structural changes and the conformational rearrangements from amine to diazonium salt, and

2) The influence of the substituent located in a para position, i.e., the nature and force of the mesomeric effect of the substituent, on the Raman modes.

Comparison between Raman experiments and DFT modeling showed that DS- $\mathrm{COOH}$ self-organized as dimers in the crystalline state. 
This paper reports on a preliminary study designed as a leadin to further examinations for investigating, improving and/ or controlling reaction pathways using synthesized diazonium salt (i.e., to examine and strengthen the nature of the interface between Gold NanoStructures (GNS, electron-beam nanolithographied SERS substrates) and organic coatings) [46].

\section{Author Contributions}

All authors have given approval to the final version of the manuscript. SB and IT contributed equally.

\section{Acknowledgments}

This work was funded by ANR ECOTECH (Production durable et technologies de l'environnement); REMANTAS project: Enhanced Raman scattering for aquatic media: a new technology for on-site analysis 2011-2014 (REMANTAS project; ANR-11-ECOT-0010). The English text was proofread by Dr. HM Kluijver. 


\section{References}

1 Kurti L, Czako B (2005) Strategic Applications of Named Reactions in Organic Synthesis. Elsevier Academic Press, Boston.

2 Meerwein H, Buchner E, van Emster K (1939) uber die Einwirkung aromatischer Diazoverbindungen auf $\alpha, \beta$-ungesättigte Carbonylverbindungen. J Prakt Chem 152: 237-266.

3 Sandmeyer T (1884) Ueber die Ersetzung der Amid-gruppe durch Chlor, Brom und Cyan in den aromatischen Substanzen. Chem Ber 17: 2650-2653.

4 Hodgson HH (1947) The Sandmeyer Reaction. Chem Rev 40: 251-277.

5 Adenier A, Barré N, Cabet-Deliry E, Chaussé A, Griveau S, et al. (2006) Study of the spontaneous formation of organic layers on carbon and metal surfaces from diazonium salts. Surf Sci 600: 4801-4812.

6 Adenier A, Cabet-Deliry E, Chausse A, Griveau S, Mercier F, et al. (2005) Grafting of nitrophenyl groups on carbon without electrochemical induction. Chem Mater 17: 491-501.

7 Betelu S, Vautrin-UI C, Chaussé A (2009) Novel 4-carboxyphenylgrafted screen-printed electrode for trace $\mathrm{Cu}(\mathrm{II})$ determination. Electrochem Commun 11: 383-386.

8 Betelu S, Vautrin-UI C, Ly J, Chaussé A (2009) Screen-printed electrografted electrode for trace uranium analysis. Talanta 80: 372-376.

9 Delamar M, Hitmi R, Pinson J, Savéant J (1192) Covalent modification of carbon surfaces by grafting of functionalized aryl radicals produced from electrochemical reduction of diazonium salts. J Am Chem Soc 114: 5883-5884.

10 Bekyarova E, Itkis ME, Ramesh P, Berger C, Sprinkle M, et al. (2009) Chemical modification of epitaxial graphene: spontaneous grafting of aryl groups. J Am Chem Soc 131: 1336-1337.

11 Combellas CM, Delamar F, Kanoufi F, Pinson J, Podvorica FI (2005) Spontaneous grafting of iron surfaces by reduction of aryldiazonium salts in acidic or neutral aqueous solution, Application to the protection of iron against corrosion. Chem Mater 17: 3968-3975.

12 Laurentius L, Stoyanov SR, Gusarov S, Kovalenko A, Lopinski GP, et al. (2011) Diazonium-Derived Aryl Films on Gold Nanoparticles: Evidence for a Carbon-Gold Covalent Bond. ACS Nano 5: 4219-4227.

13 Bahr JL, Yang J, Kosynkin DV, Bronikowski MJ, Smalley RE, et al. (2001) Functionalization of carbon nanotubes by electrochemical reduction of aryl diazonium salts: a bucky paper electrode. J Am Chem Soc 123 : 6536-6542.

14 Allongue P, Delamar M, Desbat B, Fagebaume O, Hitmi R, et al. (1997) Covalent Modification of Carbon Surfaces by Aryl Radicals Generated from the Electrochemical Reduction of Diazonium Salts. J Am Chem Soc 119: 201-207.

15 Bouriga M, Chehimi MM, Combellas C, Decorse P, Kanoufi F, et al. (2013) Sensitized Photografting of Diazonium Salts by Visible Light. Chem Mater 25: 90-97.

16 Kowalczyk A, Wagner B, Karbarz M, Nowicka AM (2015) A dual DNA biosensor based on two redox couples with a hydrogel sensing platform functionalized with carboxyl groups and gold nanoparticles. Sens Actuators B 208: 220-227.

17 Zheng M, Griveau S, Dupont-Gillain C, Genet MJ, Jolivalt C (2015) Oxidation of laccase for improved cathode biofuel cells performances. Bioelectrochemistry 106: 77-87.

18 Ahmad R, Mocaer A, Gam-Derouich S, Lamouri A, Lecoq H, et al. (2015) Grafting of polymeric platforms on gold by combining the diazonium salt chemistry and the photoiniferter method. Polymer 57: $12-20$.

19 Mahouche Chergui S, Abbas N, Matrab T, Turmine M, Bon Nguyen E, et al. (2010) Uptake of copper ions by carbon fiber/polymer hybrids prepared by tandem diazonium salt chemistry and in situ atom transfer radical polymerization. Carbon 48: 2106-2111.

20 Raicopol M, Andronescu C, Atasiei R, Hanganu A, Manea AM, et al. (2015) Synthesis of conducting azopolymers by electrochemical grafting of a diazonium salt at polypyrrole electrodes. Synth Met 206: 84-91.

21 German N, Ramanavicius A, Ramanaviciene A (2014) Electrochemical deposition of gold nanoparticles on graphite rod for glucose biosensing. Sens Actuators B 203: 25-34.

22 Wicks JZW, Jones FN, Pappas SP, Wicks DA (2007) Organic Coatings: Science and Technology. 3rd edn. John Wiley \& Sons, Hoboken.

23 Zhao J, McCreery RL (1996) Polarized Raman Spectroscopy of Metallophthalocyanine Monolayers on Carbon Surfaces. Langmuir 11: 4036-4040.

24 Badawi HM, Förner W, Ali S (2013) A comparative study of the infrared and Raman spectra of aniline and $\mathrm{o}-, \mathrm{m}-, \mathrm{p}$-phenylenediamine isomers. Spectrochim Acta 112: 388-396.

25 Frisch MJ, Trucks GW, Schlegel HB, Scuseria GE, Robb MA, et al. (2009) Gaussian 09; Gaussian, Inc: Wallingford, CT.

26 Becke AD (1993) Density-functional thermochemistry III The role of exact exchange. J Chem Phys 98: 5648-5652.

27 Lee C, Yang W, Parr RG (1988) Development of the Colle-Salvetti correlation-energy formula into a functional of the electron density. Phys Rev B 37: 785-789.

28 Fairchild SZ, Bradshaw CF, Su W, Guharay SK (2009) Predicting Raman Spectra Using Density Functional Theory. Appl Spectrosc 63: 733-741.

29 Socrates G (2001) Infrared and Raman Characteristic Group Frequencies: Tables and Charts. 3rd edn. J Wiley \& Sons, Chichester.

30 Wojciechowski PM, Zierkiewicz W, Michalska D, Hobza P (2003) Electronic structures, vibrational spectra, and revised assignment of aniline and its radical cation: Theoretical study. J Chem Phys 118: 10900-10911.

31 Badawi HM (2013) A Comparative Study of the Structure and Vibrational Spectra of Diphenylmethane, the Carcinogen 4,4'-Methylenedianiline and 4,4'-Methylenebis(N,Ndimethylaniline). Spectrochim Acta 109: 213-220.

32 Venkateswaran CS, Pandya NS (1942) The Raman spectra of organic compounds: Diethyl disulphide. Proc Indian Acad Sci A 15: 396-400.

33 Mahe L, Izuoka A, Sugawara T (1992) How a crystalline environment can provide outstanding stability and chemistry for arylnitrenes. J Am Chem Soc 114: 7904-7906.

34 Rahman ML, Kwong HC, Yusoff MM, Hegde G, Rahman MZA (2012) 4-\{(E)-2-[4-(But-3-en-1-yloxy)phenyl]diazen-1-yl\}benzoic acid. Acta Cryst E68: 2958.

35 Yu QD, Liu YY (2009) 4,4'-Azinodibenzoic acid. Acta Cryst E65: 2326.

36 Minaev BF, Bondarchuk SV, Gîrţu MA (2009) DFT study of electronic properties, structure and spectra of aryl diazonium cations. J Mol Struct 904: 14-20.

37 Hansch C, Leo A, Taft RW (1991) A survey of Hammett substituent constants and resonance and field parameters. Chem Rev 91: 165-195. 
38 Hammett LP (1937) The Effect of Structure upon the Reactions of Organic Compounds. Benzene Derivatives. J Am Chem Soc 59: 96-103.

39 Zollinger $\mathrm{H}$ (1994) Diazo chemistry: aromatic and heteroaromatic compounds, Volume $1 \mathrm{VCH}$ Publishers, New York.

40 Cygler M, Przybylska M, Elofson RM (1982) The crystal structure of benzenediazonium tetrafluoroborate, $\mathrm{C}_{6} \mathrm{H}_{5} \mathrm{~N}_{2} \bullet^{+} \mathrm{BF}_{4}{ }^{-1}$ Can J Chem 60 : 2852-2855.

41 Vincent MA, Radom L (1978) Prototypes for aliphatic and aromatic diazonium ions. An ab initio study of the methane and benzenediazonium ions. J Am Chem Soc 100: 3306-3312.

42 Coates J (2000) Interpretation of Infrared Spectra: A Practical Approach. Encyclopedia of Analytical Chemistry. Edited by Meyers RA. J. Wiley \& Sons, Chichester.
43 Lin-Vein D, Colthup NB, Fateley WG, Grasselli JG (1991) The Handbook of Infrared and Raman Characteristic Frequencies of Organic Molecules. Academic Press, San Diego.

44 Barcello JR, Otero C (1962) Infra-red spectra of the fluorinated acetic acids in condensed and vapour phase. Spectrosc Acta 18: 1231-1247.

45 Collins AJ, Morgan KJ (1963) Solvent effects in the infrared spectra of carboxylic acids Solvent effects in the infrared spectra of carboxylic acids. J Chem Soc 11: 3437-3440.

46 Betelu S, Tijunelyte I, Ignatiadis I, Ibrahim J, Gaboreau S, et al (2016) Evidence of the Grafting Mechanisms of Diazonium Salts on Gold Nanostructures. J Phys Chem B 120: 18158-18166. 